\title{
The Doctor's Dilemma: Oranges or apples?
}

$\mathrm{G}$ eorge Bernard Shaw's famous play, Doctor's Dilemma (1), is one of the attractions at the Shaw Festival this year, and recently we went to see it on a beautiful Niagara summer day, followed by a picnic beside Ball's Falls. Several weeks earlier, I had decided to read the play, with its 80page "Preface on Doctors", and was prepared for an anticlimactic experience on the day. However, the production was a delight and I gained additional insights from the live performance.

At the least, I came to three conclusions, which no doubt others have also drawn. First, the preface, written in 1911, provides so many powerful comments on the medical profession and its ethics that the play seems to have been merely an excuse for it. It contains 48 sections including topics such as "Doctors' consciences", "Why doctors do not differ", "Are doctors men of science?" and "What the public wants and will not get", to name a few. Second, both the play and the preface present the conflicting aspects of health care and medical research that remain highly relevant to this day. Third, having lived through the development of problembased learning at McMaster University, Hamilton, the play struck me as a superb example that could still be used to explore ethical issues.

The play is full of characters that we all know well. Shaw provides a detailed description of their physical, professional and psychological attributes, and, at the risk of boring my readers, it is worth providing thumbnail sketches of them. Sir Colenso Ridgeon is a clinical scientist who has discovered the "opsonic index". The character is modelled after Sir Almroth Wright, who was, for many years, Alexander Fleming's boss at St Mary's Hospital, London (called St Anne's in the play), and who applied the term "opsonin" to substances in plasma (antibodies) that facilitated phagocytosis. Sir Ralph Bloomfield Bonington, physician to the royal household and the archetype to the Harley Street physician, uses science without understanding, and is scientifically considered a "colossal humbug". Mr Cutler Walpole is a supremely confident surgeon who believes that physicians are incapable of understanding disease because they only see the outside of the patient. Sir Patrick Cullen is an Irish "grand old man of medicine" who knows that there is nothing new in medicine, is rightly skeptical of medical advances and remembers patients that have died under his care. Dr Leo Schutzmacher is a Jewish general practitioner who attrib- utes his great success to marketing (he has "Cure Guaranteed" under his office name plate). Dr Blenkinsop is a down-at-heel general practitioner who practices in a poor part of London and defers to his more successful colleagues; it later transpires that he has tuberculosis. The other main characters are the patient, Louis Dubedat, an

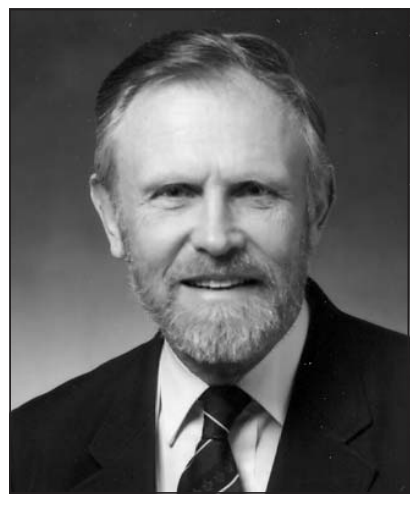
extremely talented artist who has pulmonary tuberculosis, and his beautiful wife Jennifer. Mrs Dubedat has read of Sir Ridgeon's medical research in the announcement of his Knighthood, and has come to plead with him to take on her husband's case. She arrives at his home just as the other doctors come to congratulate him on his honour. A discussion ensues between the doctors as to how the case should be managed. Sir Ridgeon would treat him by tuberculosis vaccination, but only if the opsonic index is 0.8 (and not 1.0 - Shaw clearly understood bogus mathematics and statistics!); however, he cannot afford to take on another patient (we are not told the source of his funding). Sir Bonington would "stimulate the phagocytes" with vaccines and antitoxins, no matter what their recognized uses are or what the opsonic index is, to the dismay of Sir Ridgeon. Mr Walpole believes that the patient has blood poisoning, and that the "nuciform sac" has to be removed. Sir Cullen believes that the proposed treatments are likely to kill the patient, who either will or will not recover. Dr Schutzmacher would presumably give him a coloured mixture and convince him that it will cure him. Dr Blenkinsop would refer him to a consultant, but would tell him to take a pound of ripe greengages to make him feel better. As if this was not enough for a good debate on medical ethics, Sir Ridgeon falls for Louis' wife, and all of them are bowled over by the quality of Louis' art, despite his being a blackguard who tries to borrow money from them all. During the debate, Sir Ridgeon shows enough insight to express the view that "it's always the patient who has to take the chance when an experiment is necessary"; his conflict of interests (he is also an art collector) leads him to recommend Sir Bonington, with disastrous deterioration in the patient's condition and speedy death on stage. Dr Blenkinsop, 
on the other hand, is taken on by Sir Ridgeon, and, the opsonic index being propitious, makes a remarkable recovery from his tuberculosis.

You may be wondering what this has to do with the Canadian Respiratory Journal. In the current issue, you will find an article written by Dr John Miller and his colleagues (pages 329-332) on the ethical concept of equipoise in clinical research as it applies to their randomized trial of lung volume reduction surgery (LVRS) for emphysema. If Shaw were to rewrite his play on this topic, no doubt he would incorporate the notion that the patient with emphysema has brought the problem on himself through cigarette smoking, and would also collect a group of physicians to debate the pros and cons of various therapeutic measures. There would be a scientist wanting to use antitrypsin therapy, a physiologist wanting to improve forced expiratory volume in $1 \mathrm{~s}$ with various drugs, a physician wanting to reduce disability and handicap through a rehabilitation program, a surgeon wanting to remove the useless lung, an epidemiologist wanting to increase quality-adjusted life years and an economist wanting to reduce the economic burden to society. Among this group, the concept of equipoise might be difficult to apply, for each would have their own view on what would constitute valid evidence to place on the balance. Can changes in forced expiratory volume in $1 \mathrm{~s}$ be placed on the same scale as quality-adjusted life years? This is where apples and oranges come in.

Benjamin Freedman introduced the concept of 'clinical equipoise', which states that genuine uncertainty in the expert medical community regarding a proposed treatment is a prerequisite for a clinical trial (2). What we need, but will never have, is a method to weigh all the different factors that contribute to a decision to advise a patient with emphysema to have LVRS. Perhaps because of this, Miller and his colleagues propose 'community equipoise' as a concept that should be considered in relation to whether a trial of LVRS is justified. If analogous to clinical equipoise, community equipoise implies genuine uncertainty in the patient community to which LVRS is aimed. However, when we get down to it, how are we to judge whether equipoise exists? As Miller points out, patients need access to all of the available information regarding different aspects of the treatment; they need to know the quality of all of the apples and oranges. While we may all agree that informed consent to take part in a trial implies genuine uncertainty on the part of the patient who has access to all the facts, there may not be agreement regarding how community equipoise is to be achieved or judged.

Ethical problems facing the medical profession were clearly described by Shaw in 1906. Ethical issues involved in clinical research came to prominence after World War II, leading to the 10-point Nuremberg Code in 1948 and the Helsinki Declaration in 1964. Rereading the 600-page issue of the American Academy of Arts and Sciences' 1969 publication Dadalus (3), it seems to me that 30 years later, we are still grappling with many of the same problems that were discussed by its eminent contributors, and I am not sure whether equipoise helps in their resolution. Dialogue and new ideas are still essential if we are to meet scientific needs, the needs and rights of patients and the needs of society. Such new approaches will also have to encompass the new concepts inherent in 'postnormal' science, with its randomness, nonlinearity, complexity and unpredictability. Within these concepts, there is also a new awareness of value commitment and the importance of different perspectives that contribute to policy decisions. Thus, evidence gained from basic science approaches and the experience of experts remain important, but they are weighed by what has been termed the 'extended peer community', which brings its own 'real life' perspective to bear on the topic (4). A plea for a 'third dimension' in evidence-based medicine applied to general practice has been made by Sweeney et al (5). While accepting the validity of both statistical significance and clinical significance, they make a case for 'personal significance', which requires a dialogue between the practitioner and the patient. The patient is thereby able to bring personal experience of illness and unique values to bear on the decision to take a certain course of action.

The case for continuing trials of LVRS is well made by Dr Miller and his colleagues. Respirologists are hoping for a disturbance in clinical equipoise at the conclusion of the Canadian trial, together with the scientific basis for indications for this surgery. We are also hoping for information on the many factors that determine outcome in an individual patient. Eventually, we will have enough evidence to disturb community equipoise, and enough to repay our debt to all the patients that have agreed to take part in it.

\section{Norman L Jones Editor-In-Chief Canadian Respiratory Journal}

\section{REFERENCES}

1. Shaw GB. The Doctor's Dilemma. A tragedy. Definitive text. London: Penguin Books, 1957.

2. Freedman B. Equipoise and the ethics of clinical research. New Engl J Med 1987;317:141-5.

3. Beecher HK et al. Ethical aspects of experimentation with human subjects. Proceedings of the American Academy of Arts and Sciences. Dædalus 1969. Boston: American Academy of Arts and Sciences, 1969:219-597.

4. Sardar Z, Abrams I. Introducing chaos. New York: Totem Books, 1999.

5. Sweeney KG, MacAuley D, Gray DP. Personal significance: the third dimension. Lancet 1998;351:134-6. 


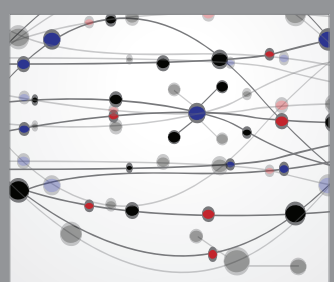

The Scientific World Journal
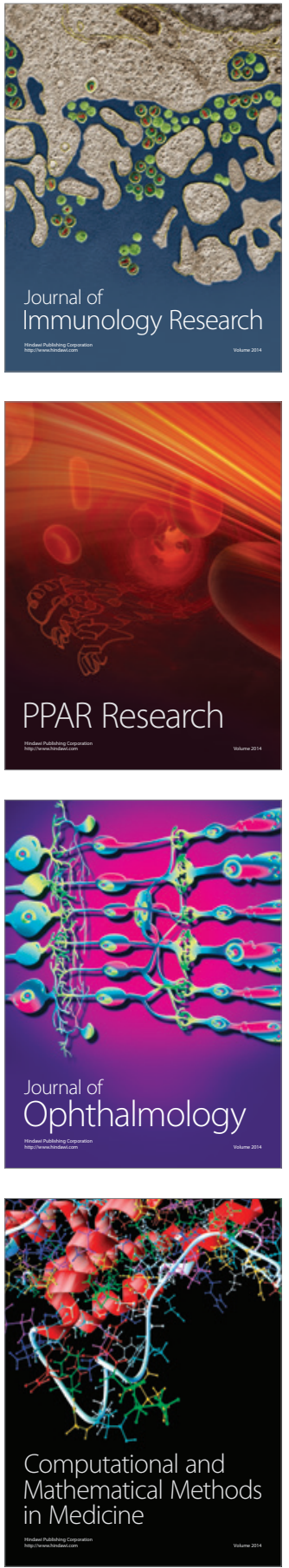

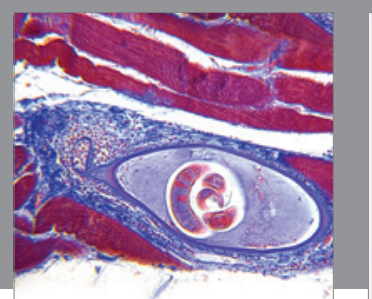

Gastroenterology Research and Practice

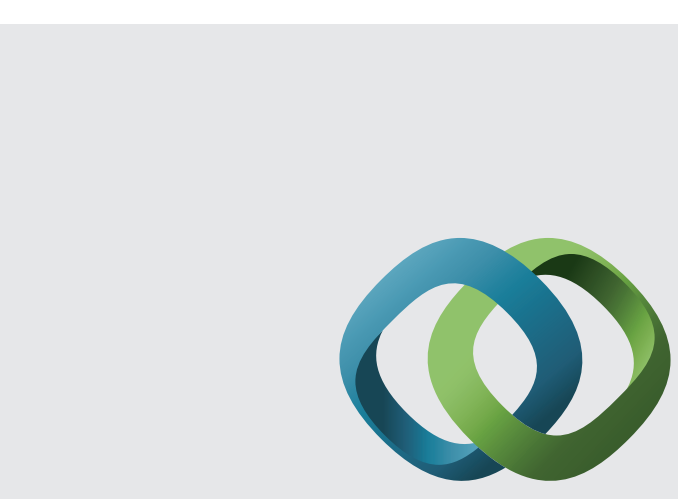

\section{Hindawi}

Submit your manuscripts at

http://www.hindawi.com
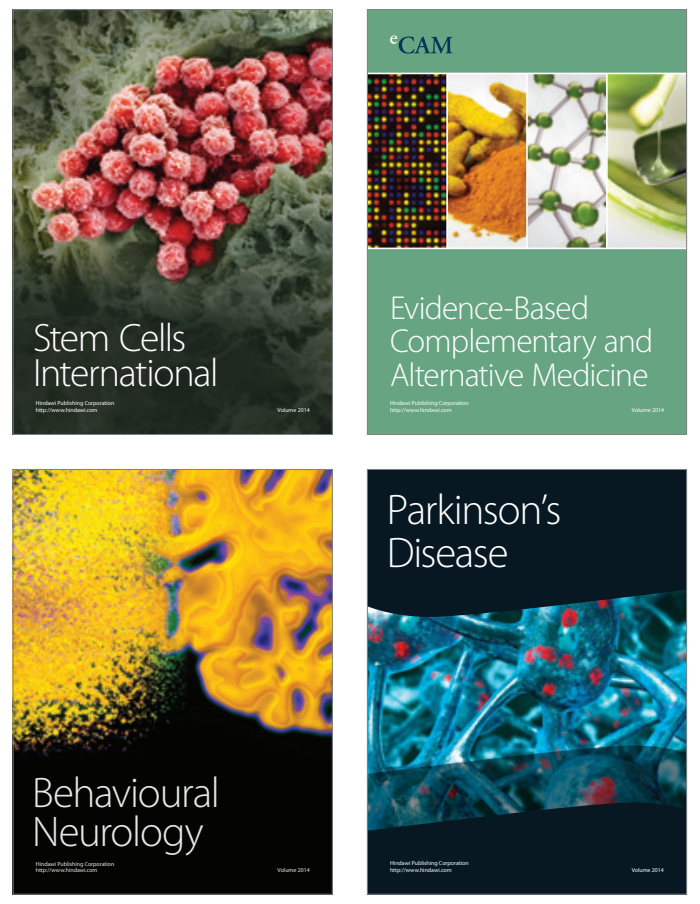
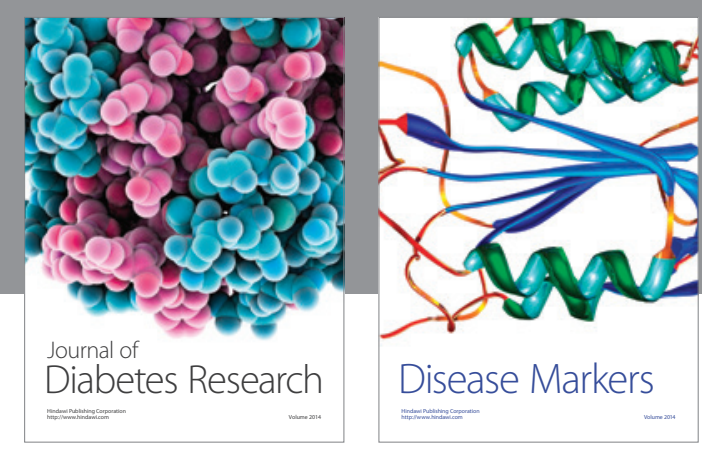

Disease Markers
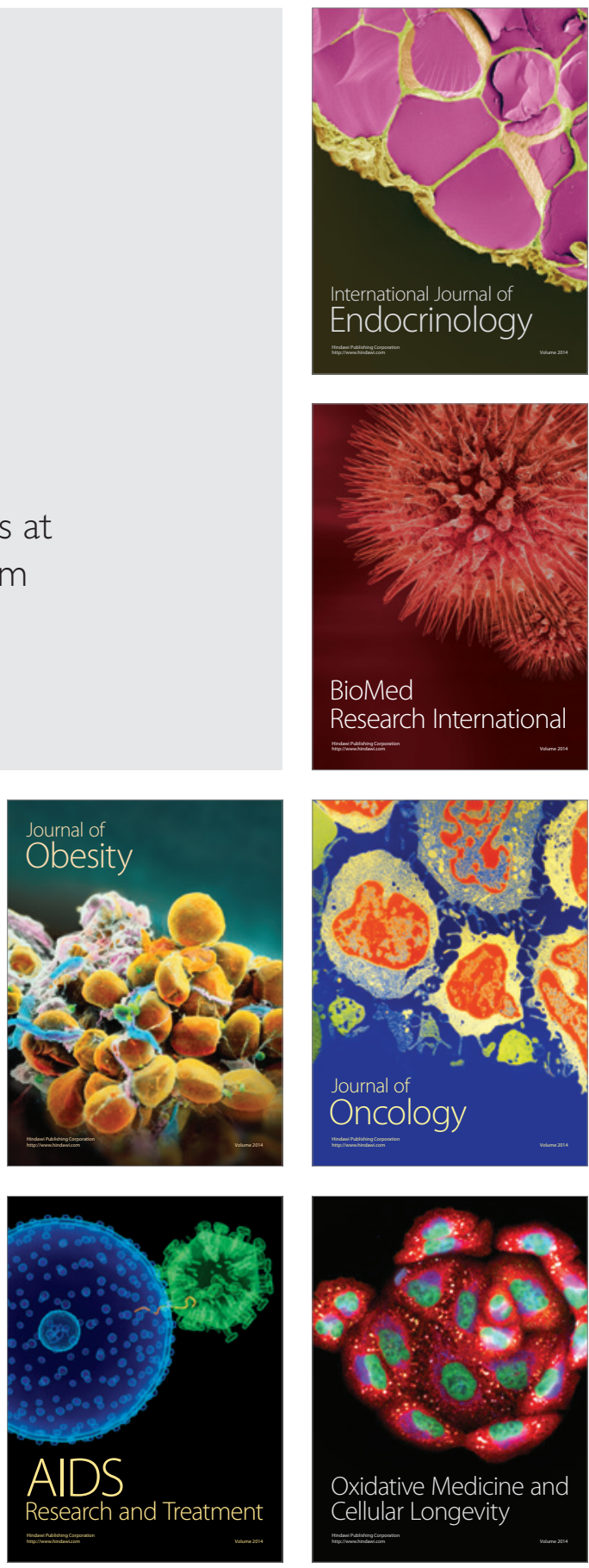